\title{
The Production of Blue Cheese with the Addition of Nonpathogenic Strain of Klebsiella pneumoniae and Fortification of Folic Acid and Iron
}

\author{
WIDYA AGUSTINAH* AND FLORENTINUS GREGORIUS WINARNO \\ Faculty of Biotechnology, Universitas Katolik Indonesia Atma Jaya, \\ Jalan Jenderal Sudirman 51, Jakarta 12930, Indonesia
}

\begin{abstract}
Blue cheese is a semi-soft ripened cheese that involves the growth of Penicillium roqueforti in the ripening process. Cheese has a longer shelf life compared to raw milk and the production of cheese will give added value to the finished product, which, therefore, can benefit local dairy farmers in Indonesia. The objective of this study was to produce a new variant of blue cheese which was made from a mixture of fresh cow's milk (Frisian Holstein cow) and skimmed milk powder and which had a high vitamin B12, folic acid, and iron content. Blue cheeses for this study were made by milk fermentation with the addition of a nonpathogenic strain of Klebsiella pneumoniae in the cheese preparation and fortification of folic acid and iron. This study showed that blue cheeses had been successfully made from a mixture of fresh cow's milk and skimmed milk at a ratio of $1: 1$ and acceptable by 42 untrained panelists. Compared to the commercial blue cheese, the addition of $K$. pneumoniae $(0.8 \% \mathrm{v} / \mathrm{v})$ and fortification $\left(0.08 \mathrm{~g} \mathrm{~L}^{-1}\right.$ of premix) had positive effects in increasing the amount of vitamin B12, folic acid, and iron up to $2.7,13.64$, and $102.86 \mathrm{ppm}$ on dry-weight basis, respectively. However, blue cheese made without K. pneumoniae was the most preferred and had the highest scores for texture, taste and aroma.
\end{abstract}

Key words: blue cheese, fortification, Klebsiella pneumoniae, Penicillium roqueforti

Cheese is a fermented product from milk, often from cow's milk. However, milk from other farm animals is sometimes utilized as raw material for cheese production. Cheese has a similar nutritional content (in dry basis) to fresh milk, except that the nutritional components in cheese are always more concentrated due to its different water content.

The blue cheese (e.g. Roquefort) is an example of semisoft cheese which has been ripened using the blue mold (Penicillium roqueforti) and some species of bacteria. Both of them play an important role in the quality and flavor of the blue cheese (Kosikowski 1982). The health benefit of blue cheese was studied by Yasuda et al. (2010) and the result showed that a highly ripened blue cheese had a potential role in the prevention of leukemic cell proliferation.

Unfortunately, unlike in subtropical countries, the methods and techniques for cheese making are not yet popular in Indonesia, particularly among small scale Indonesian dairy farmers. Since raw fresh milk is perishable, the bargaining power of dairy farmers is also very limited. Some of the fresh milk often gets discarded because it becomes spoiled before it can be sold to the milk industry.

For those reasons, the process or technology to give added value to the milk is very important. The technology for making cheese is considered very important and is likely to be the best choice. In the United States, high temperature short time (HTST) pasteurized milk has a shelf life of approximately 10 to 14 days, while the shelf life of cottage cheese (with a maximum $80 \% \mathrm{w} / \mathrm{w}$ moisture content) is 21 to 28 days (Chen and Hotchkiss 1991). Blue cheese has a longer shelf life due to its lower moisture content (35-45\% $\mathrm{w} / \mathrm{w})$. The initial quality variation of dairy products, such as cheese and pasteurized milk, affects the ultimate shelf life (Hotchkiss et al. 2006). Aside of the longer shelf life, cheese

*Corresponding author, Phone: +62-21-5703306; Fax: +62-21-5719060; E-mail: widya.agustinah@atmajaya.ac.id also has much higher price or higher added value. Indirectly, it will bring much higher bargaining power to the dairy industries.

Anemia is a widespread public health problem that commonly occurs among females and children, especially in the developing countries. Anemia also becomes an indicator of both poor nutrition and poor health. The global prevalence of anemia due to iron deficiency in pregnant women and non-pregnant women is $41.8 \%$ and $30.2 \%$, respectively (McLean et al. 2007). In South East Asia, 45.7\% of nonpregnant women of reproductive age and $65.5 \%$ of preschool-age children are reported as anemic (WHO 2008). The other types of anemia are macrocytic anemia, which is due to the lack of folic acid, and pernicious anemia, which is due to an inadequate intake and malabsorption of vitamin $B 12$.

The common food vehicles for folic acid and iron fortification are cereal products, milk, sugar, salt and coffee (Hurrell 1997; Forssén et al. 2000). Cheese is not a staple food and is usually consumed as a delicacy by the society of medium and higher economy class. As far as the mass production concerns, cheese is not considered the best vehicle for enrichment with vitamin B12 and fortification with folic acid and iron because it is not generally consumed by people, especially females in Indonesian society, as compared to wheat flour, cereals, or other food products. However, concerning that cheese is made of milk as raw material which is low in iron, we would like to introduce a new cheese variant that is relatively high in iron content, as well as vitamin B12 and folic acid.

In this study, the most appropriate conditions for blue cheese production was assessed and optimized. In our research design, the process would incorporate a nonpathogenic strain of Klebsiella pneumoniae, which had been known as a producer of vitamin B12 in tempe. Klebsiella pneumoniae isolated from soybean tempe had 
been shown not to possess the genes encoding the enterotoxin Shiga-like toxin SLT-IIA, heat-labile enterotoxin LT Ih and heat-stable enterotoxin ST Ih (Keuth and Bisping 1994).

The objective of the research work was to produce a new variant of blue cheese which included $K$. pneumoniae from tempe and was fortified with folic acid and iron. Vitamin $\mathrm{B} 12$, folic acid, and iron are vital for the production of red blood cells. Therefore, the consumption of blue cheese with those added components would be beneficial to prevent anemia, especially for young and adult women.

\section{MATERIALS AND METHODS}

Samples. Milk samples consisted of fresh milk of Frisian Holstein cow from Bogor dairy farmer (the milk was purchased in the form of raw liquid without pasteurization) and skimmed milk (Sun Lac Low Fat ${ }^{\circledR}$, Australia) in the form of a dry powder at a ratio of $1: 1$. Culture microorganisms used were Lactobacillus delbrueckii subsp. bulgaricus, Streptococcus thermophilus, and a nonpathogenic strain of $K$. pneumoniae isolated from soybean tempe. They were obtained from Microbiology Laboratory, PT Mbrio Biotekindo, Indonesia. As a reference sample, commercial cheese (Viking - Danish Blue Cheese) was used as a control (T4) and as the isolation source of $P$. roqueforti culture. Rennet in the liquid form was obtained from PT Natura Cheese. The premix for mineral fortification was obtained from Bogasari Flour Mill, PT Indofood Sukses Makmur, Tbk. Blue cheeses produced and purchased for this experiment were coded T1, T2, T3, and T4 with details as appeared in Table 1. Blue cheeses T1, T2, and T3 were different in their addition of $K$. pneumoniae and premix, while T4 was a commercial blue cheese and used as a control.

Isolation and Identification of $\boldsymbol{P}$. roqueforti. Single loop of commercial cheese samples was streaked on Potato Dextrose Agar (PDA, Oxoid) acidified with $10 \mathrm{~mL} \mathrm{~L}^{-1}$ of $10 \%(\mathrm{w} / \mathrm{v})$ sterile tartaric acid and incubated at room temperature for 5-7 days. Single colonies were purified on PDA slant agar and incubated at $25^{\circ} \mathrm{C}$ for 5-7 days until sporulation occurred. The light microscope was used to morphologically identify the $P$. roqueforti mold isolate.

Preparation of Bacteria and Mold Cultures. Pure culture of $L$. delbrueckii subsp. bulgaricus and $S$.

Table 1 Composition of blue cheese samples

\begin{tabular}{lcc}
\hline Samples Code & Klebsiella pneumoniae & Premix $*$ \\
\hline T1 & - & + \\
T2 & + & - \\
T3 & + & + \\
T4 (control)** & - & -
\end{tabular}

*According to the certificate of analysis issued by Fortitech AP on March 2008 , the premix composed of $2.55 \mathrm{~g} / 100 \mathrm{~g}$ thiamine, $3.96 \mathrm{~g} / 100 \mathrm{~g}$ vitamin $\mathrm{B} 2,1.92 \mathrm{~g} / 100 \mathrm{~g}$ folic acid, $50.1 \mathrm{~g} / 100 \mathrm{~g}$ iron and $31.1 \mathrm{~g} / 100 \mathrm{~g}$ zinc.

**Control cheese (T4) was a commercial blue cheese (Viking - Danish Blue Cheese) thermophilus were subcultured in de Mann Rogosa Sharp (MRS, Oxoid) broth and then incubated at $37^{\circ} \mathrm{C}$, overnight. After that, $1 \mathrm{~mL}$ of each culture was pipetted into a-100 ml $15 \%(\mathrm{w} / \mathrm{v})$ pasteurized skim milk medium to make a working starter solution. After overnight incubation at $37^{\circ} \mathrm{C}$, the starters were ready to use. A pure culture of $K$. pneumoniae nonpathogenic strain was grown in nutrient agar (NA, Oxoid) medium for $2 \mathrm{~d}$ at $37^{\circ} \mathrm{C}$. Confirmation of the culture was done by Gram staining. Each tube containing the culture of $K$. pneumoniae, previously grown in NA medium, was suspended with $6 \mathrm{~mL} 0.85 \%(\mathrm{w} / \mathrm{v}) \mathrm{NaCl}$ before inoculated into the milk. The isolate of $P$. roqueforti was grown in PDA medium at $25^{\circ} \mathrm{C}$ for 5-7 d until green conidia were produced. An aliquot of $8 \mathrm{~mL} 0.85 \%(\mathrm{w} / \mathrm{v}) \mathrm{NaCl}$ was suspended into the culture before inoculated into the curd.

Production of Fortified Blue Cheese. In the blue cheese making, the inoculation of $K$. pneumoniae and $P$. roqueforti spores and the addition of premix were done before curd pressing. The milk was pasteurized at $80^{\circ} \mathrm{C}$ for $10 \mathrm{~min}$, then filtered and cooled down to $35^{\circ} \mathrm{C}$, followed by the inoculation of lactic acid bacteria starter $(1 \% \mathrm{v} / \mathrm{v} L$. delbrueckii subsp. bulgaricus and 1\% v/v S. thermophilus) and culture of $K$. pneumoniae $(0.8 \% \mathrm{v} / \mathrm{v})$, the addition of rennet $(0.01 \% \mathrm{v} / \mathrm{v}), \mathrm{CaCl}_{2}(0.01 \% \mathrm{w} / \mathrm{v})$, and $\mathrm{KNO}_{3}(0.01 \%$ $\mathrm{w} / \mathrm{v})$. The milk mixture was stirred continuously for $30 \mathrm{~min}$ and incubated for $6 \mathrm{~h}$ at $43^{\circ} \mathrm{C}$ until the curd was formed and separated from the whey. The process was followed by cutting the curd and draining the whey. Spores of $P$. roqueforti were then inoculated into the curd, stirred to homogenize the mixture and incubated at room temperature for $3 \mathrm{~h}$. A sample of mineral premix of the amount $0.08 \mathrm{~g}$ was suspended in $1 \mathrm{~mL}$ of distilled water and then added to the curd. The curd was pressed for $10 \mathrm{~min}$. Afterwards, the curd was molded, rubbed with salt ( $4 \%$ of the curd weight) at the surface, perforated with sterile toothpicks and incubated at room temperature for $1 \mathrm{~d}$. Perforated curd was then ripened in the refrigerator $\left(6-8^{\circ} \mathrm{C}\right)$ at $\mathrm{RH} 80 \%$ for 3 months. Each experiment was done in duplicate.

Chemical Analysis. Several analyses had been done after 28 days of maturation. Blue cheese samples were analyzed for moisture, ash, fat, and protein content as outlined by the Indonesian National Standardization Organization (BSN 1992); vitamin B12 and folic acid by high performance liquid chromatography (HPLC) using UV/Visible spectrophotometric detection (Holstter 1994); and iron content by Atomic Absorption Spectrophotometer (AAS) at an iron specific wavelength of $248 \mathrm{~nm}$ (BSN 1998).

The amount of vitamin B12, folic acid, and iron in all cheese samples were calculated in each $30 \mathrm{~g}$ serving of blue cheese. These vitamin and mineral contents were compared to the Recommended Dietary Allowance (RDA) value to meet the requirements for females at age 19 to 65 years old, i.e. $2.4 \mu \mathrm{g}$ for vitamin B12, $400 \mu \mathrm{g}$ for folic acid, and $18 \mathrm{mg}$ for iron (FAO/WHO 2004), so that the percentage of Recommended Daily Value (\% RDV) could be determined.

Sensory Evaluation Test. Three cheese samples (T1, T2, and T3) and a control (T4) were evaluated by panelists 
for the preference of sensory characteristics (texture, taste, and aroma). Preference test was conducted using the hedonic scale by random untrained panelists from 42 students ( 27 females and 15 males at the age of 20-22 years old) of the Faculty of Biotechnology, Atma Jaya Catholic University. Prior to the real sensory preference test, panelists were given a sample of commercial blue cheese to familiarize themselves with the blue cheese product. Scores used for the hedonic scale were in the range of 4 to 8 (score 4 for the most disliked and score 8 for the most preferred characteristics). The data were then analyzed using a single factor analysis of variance (Anova) in Microsoft Excel 2003 software to find the significance difference $(p<0.05)$ among each character.

\section{RESULTS}

Mold Identification and Bacteria Confirmation. Mold isolated from commercial blue cheese (Danish blue cheese) was confirmed as a genus of Penicillium. The mold isolate produced green conidia in PDA medium and showed the specific characteristics of septate hyphae, phyalid, conidiophores, and conidia. The mold was later used in the blue cheese making in this experiment. The isolate of $K$. pneumoniae nonpathogenic strain formed a mucoid colony. It was confirmed by Gram staining as a rod, Gram negative bacteria (data not shown) and was used as vitamin B12producing inoculums in the cheese making.

Chemical Analysis. The results of chemical analysis on dry-weight basis are shown in Table 2. The fat and ash contents in $\mathrm{T} 1, \mathrm{~T} 2$, and $\mathrm{T} 3$ samples were lower than in control, but the protein content (on dry-weight basis) of the three samples were higher than in the control.

The chromatograms of vitamin B12 and folic acid content in T3 sample are shown in Fig 1. Vitamin B12 and folic acid were detected at a retention time $\pm 6.7 \mathrm{~min}$ and 22.1 min respectively. The overall results of vitamin B12, folic acid, and iron content in all blue cheese samples can be seen in Table 2. The commercial blue cheese (control) did not contain any vitamin B12 or iron and only contained a low concentration of folic acid ( $0.11 \mathrm{ppm}$ on a dry-weight basis). On the contrary, blue cheese made with either the premix fortification (T1) or the addition of $K$. penumoniae (T2), could increase the vitamin B12, folic acid, and iron contents in the blue cheese. Additionally, the amount of vitamin B12, folic acid, and iron in the T2 sample were lower than in the $\mathrm{T} 1$ sample. The T3 sample which contained K. pneumoniae and premix showed the highest amount of vitamin B12, folic acid, and iron: $2.70,13.64$, and 102.86 ppm, respectively.

The amount and \% RDV of vitamin B12, folic acid, and iron in all cheese samples in each $30 \mathrm{~g}$ serving of blue cheese was shown in Table 3 . One 30 -g serving of blue cheese provided more than $500 \%$ RDV of vitamin B12, 16.50 to $39 \%$ RDV of folic acid, and 0.24 to $4.53 \%$ RDV of iron.

Sensory Evaluation Test. Based on Anova single factor results, the texture and aroma of the three blue cheese samples were not significantly different (Fig 2). The T1 sample had the highest mean score of texture, flavor, and aroma preference, i.e. 6.02. The taste preference among the three cheese samples was significantly different $(\mathrm{p}<0.05)$. In addition, cheese samples produced in this experiment were all acceptable by the panelists with the lowest score of taste preference is 5.21 for T3. The taste preference of T3 is within the range of 5 (not liked) and 6 (neutral). The acceptability of the cheese samples is based on the mean preference score of texture, taste, and aroma at $>5$ of each sample.

\section{DISCUSSION}

Sequence In this study, blue cheese could be made from a mixture of fresh cow's milk and skimmed milk at a ratio of $1: 1$. The curd had firmer texture than the curd produced from $100 \%$ fresh cow's milk. The success of using a skimmed

Table 2 Chemical composition (dry basis) of blue cheese after 28 days of ripening

\begin{tabular}{lcccc}
\hline \multirow{2}{*}{$\begin{array}{c}\text { Chemical } \\
\text { composition }\end{array}$} & T1 & T2 & T3 & T4 (Control) \\
\cline { 2 - 5 } & & & & \\
\hline Dry matter (\%) & $41.26^{\text {ae }}$ & $39.26^{\text {be }}$ & $38.13^{\text {ce }}$ & $54.47^{\mathrm{d}}$ \\
Protein (\%) & $47.36^{\text {ae }}$ & $52.39^{\text {be }}$ & $47.55^{\text {ce }}$ & $35.19^{\mathrm{d}}$ \\
Fat (\%) & $30.85^{\text {ae }}$ & $29.72^{\text {be }}$ & $27.12^{\mathrm{c}}$ & $52.51^{\mathrm{d}}$ \\
Ash (\%) & $7.90^{\text {ae }}$ & $5.50^{\mathrm{b}}$ & $7.00^{\mathrm{ce}}$ & $9.42^{\mathrm{d}}$ \\
Vitamin B12 (ppm) & $1.50^{\mathrm{a}}$ & $1.07^{\mathrm{b}}$ & $2.70^{\mathrm{c}}$ & $0.00^{\mathrm{d}}$ \\
Folic acid (ppm) & $5.33^{\mathrm{a}}$ & $4.20^{\mathrm{b}}$ & $13.64^{\mathrm{c}}$ & $0.11^{\mathrm{d}}$ \\
Iron (ppm) & $36.09^{\mathrm{a}}$ & $5.27^{\mathrm{b}}$ & $102.86^{\mathrm{c}}$ & $0.00^{\mathrm{d}}$ \\
\hline
\end{tabular}

*T1 was added with premix; T2 was added with Klebsiella pneumoniae; T3 was added with both premix and $K$. pneumoniae; and T4 was a commercial blue cheese (without K. pneumoniae or premix addition).

Different superscript in each row shows significant difference $(\mathrm{p}<0.05)$.
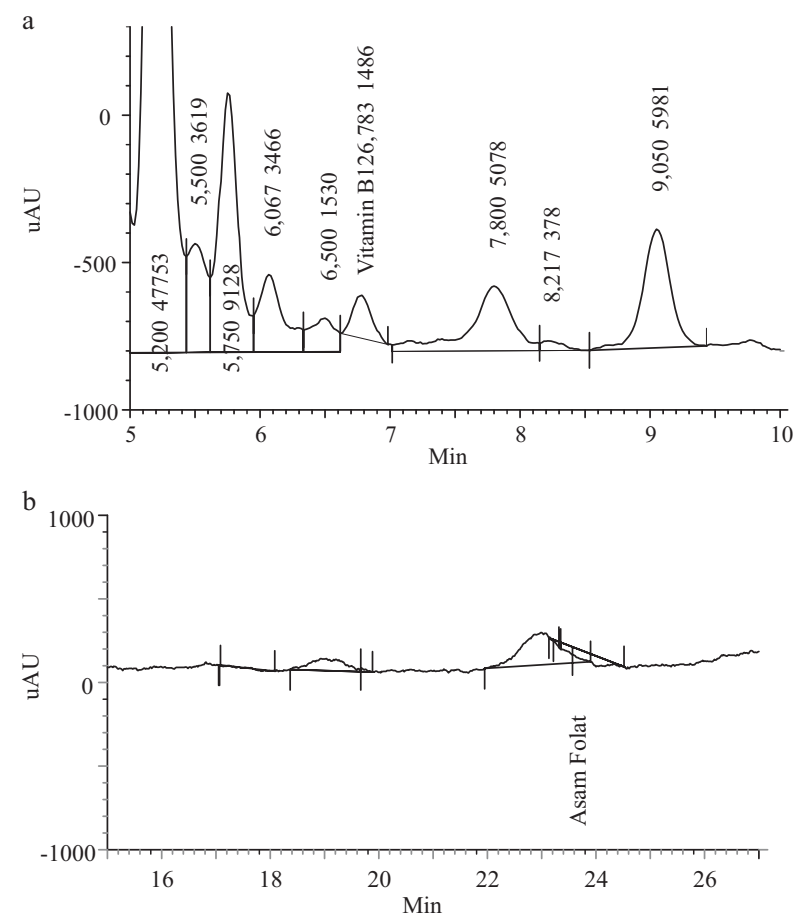

Fig 1 Chromatograms of vitamin B12 (a) and folic acid (b) in the cheese sample (added with premix and Klebsiella pneumoniae). 
Table 3 The amount and \% RDV of some nutritional components per $30 \mathrm{~g}$ serving of blue cheese

\begin{tabular}{ccccccc}
\hline \multirow{2}{*}{ Samples } & \multicolumn{2}{c}{ Vitamin B12 } & \multicolumn{2}{c}{ Folic Acid } & \multicolumn{2}{c}{ Iron } \\
\cline { 2 - 7 } & $\begin{array}{c}\text { Amount } \\
(\mu \mathrm{g})\end{array}$ & $\begin{array}{c}\text { RDV } \\
(\%)\end{array}$ & $\begin{array}{c}\text { Amount } \\
(\mu \mathrm{g})\end{array}$ & $\begin{array}{c}\text { RDV } \\
(\%)\end{array}$ & $\begin{array}{c}\text { Amount } \\
(\mathrm{mg})\end{array}$ & $\begin{array}{c}\text { RDV } \\
(\%)\end{array}$ \\
\hline T1 & 18.60 & 775.00 & 66.00 & 16.50 & 0.45 & 2.48 \\
T2 & 12.60 & 525.00 & 49.50 & 12.38 & 0.06 & 0.35 \\
T3 & 30.90 & 1287.50 & 156.00 & 39.00 & 1.18 & 6.54 \\
T4 (control) & 0.00 & 0.00 & 1.80 & 0.45 & 0.00 & 0.00 \\
\hline
\end{tabular}

RDV: recommended daily value. T1 was added with premix; T2 was added with Klebsiella pneumoniae; T3 was added with both premix and $K$. pneumoniae; and T4 was a commercial blue cheese (without $K$. pneumoniae or premix addition).

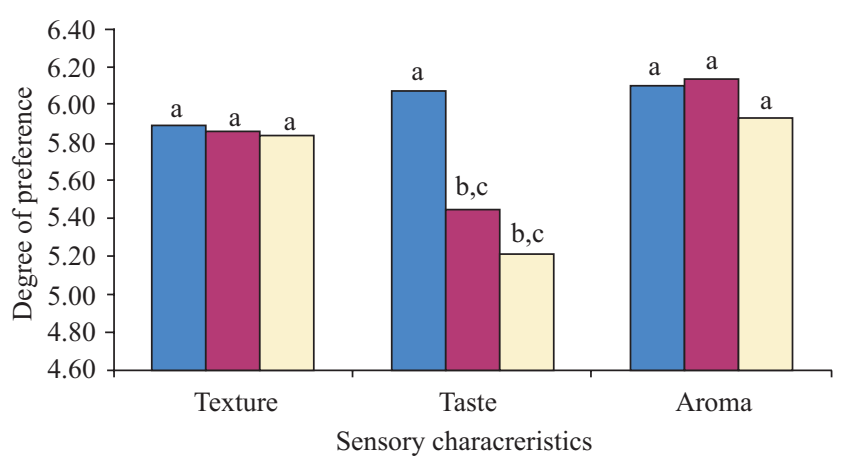

Fig 2 The preference scores of texture, taste and aroma of T1 ( $\square)$, T2 ( $\square$ ), and T3 ( $\square$ ) blue cheese samples. T1 was added with premix; T2 was added with Klebsiella pneumoniae; T3 was added with both premix and $K$. pneumoniae. The significant difference $(\mathrm{p}<0.05)$ is represented by different superscripts at each characteristic.

milk mixture in blue cheese production is important for local dairy farmers to cope with the low yields of cow's milk.

As shown in Table 2, the protein content in the experimental blue cheese was higher; while the fat content $(\leq 30 \% \mathrm{w} / \mathrm{w}$ dry-weight basis) was lower than the commercial blue cheese. The increasing protein content in the experimental blue cheese samples was due to the addition of skimmed milk.

A low fat content would give an undesirable crumbly texture and less moist texture to the cheese. A low dry matter due to the high moisture content $( \pm 60 \% \mathrm{w} / \mathrm{w})$ observed in the experimental blue cheese indicated the lack of pressure applied to the curd and the short ripening time of the cheese (28 d). However, the higher moisture content resulted in the softer texture of the cheese product so that it could be consumed without grating. Additionally, higher yields in the cheese product could be reached due to the greater moisture content and the more effective recovery of proteins and fats (Caponio et al.2001).

Blue cheese in this study had a different value of proximate composition compared to common blue cheese. It is stated by Kosikowski (1982) that blue cheese should contain at least $50 \%$ milk fat in dry matter and not more than $46 \%$ water content. Therefore, the new variant of blue cheese might have been produced in Indonesia.

The $K$. pneumoniae strain used in this research was considered safe and nonpathogenic since it was isolated from soybean tempe. According to Shurtleff and Aoyagi (1986), virtually, all commercial tempe contains natural occurring, beneficial strain of Klebsiella which grows naturally and symbiotically with tempe mold. There were pathogenic and nonpathogenic strains of $K$. pneumoniae, and only nonpathogenic strains had been found in tempe. Keuth and Bisping (1993) reported that a K. pneumoniae strain in tempe could form large amount of vitamin B12, a vitamin which was rarely found in the vegetarian foodstuffs, and in 1994, they proved that $K$. pneumoniae isolated from tempe did not possess the enterotoxin genes.

Vitamin B12, folic acid, and iron content in the cheese samples were higher than in the control (commercial Danish blue cheese). Our results showed that fortification $\left(0.08 \mathrm{~g} \mathrm{~L}^{-1}\right.$ premix) and the addition of a nonpathogenic strain of $K$. pneumoniae $(0.8 \% \mathrm{v} / \mathrm{v})$ were successfully undertaken and had positive effects in increasing the amount of vitamin B12, folic acid and iron in the cheese although vitamin B12 was not the component of the premix. The premix composition was shown in Table 1.

Blue cheese without premix addition (T2) contained the least amount of vitamin B12, folic acid, and iron among the experimental blue cheese. It means that the premix was important and could significantly increase vitamin B12, folic acid, and iron content in the blue cheese. The premix itself contained other vitamins and minerals, such as thiamine, vitamin B2, and zinc. Therefore, premix (fortification) might also support the growth of $K$. pneumoniae and the production of vitamin B12.

Moreover, the results also indicated that addition of the premix alone (T1) promoted significant increase in vitamin B12 content as compared to T2 and T4 (control). It means that the predetermined level of premix addition was too high.

Folate represents an important vitamin B that is required in human metabolic pathways. Since there is a growing evidence that a low folate status increases the risk of neural tube defects during early pregnancy (Daly et al. 1995), occlusive vascular disease (Boushey et al. 1996), and colon cancer (Glynn and Albanes 1994); several experts and authorities advocate an increase in the consumption of folates, especially for women of reproductive age. Alevel of $400 \mu \mathrm{g}$ folate per day has been suggested (Bailey 1995). According to Forssén et al. (2000), most cheese variants contain between 10 to $40 \mu \mathrm{g}$ folate per $\mathrm{kg}$. Ripened soft cheeses may contain up to $100 \mu \mathrm{g}$ folate per $100 \mathrm{~g}$.

In this study, the modified cheeses produced, either with the addition of a nonpathogenic strain of $K$. pneumoniae and/or the fortification of premix, could meet the RDA for vitamin B12, folic acid, and iron for females of 1965 years old. It was only the vitamin B12\%RDV that exceeded $100 \%$. According to Herbert (1988), larger amounts of vitamin B12 consumption was not reported to have any added value for better health or longer life. Morris et al. (2005) also reported that a high folate intake was more likely associated with cognitive decline in older people than a high vitamin B12 intake. Indeed, the level of cheese consumption by Indonesian people is less than $30 \mathrm{~g}$; thus, the $\%$ RDV for vitamin B12 would be lower. 
Among the 42 panelists involved in the sensory evaluation, $64 \%$ of them were females at the age of $20-22$ years old. Blue cheese samples without $K$. pneumoniae (T1) were the most preferred by the panelists and had the highest scores of preference for texture, taste and aroma at $\mathrm{p}<0.05$. The taste preference was lower in T2 and T3 samples. This result showed that the addition of $K$. pneumoniae, as well as the premix in T3 sample, affected the blue cheese taste negatively although the addition of those could increase the amount of vitamin B12 in cheese.

From all the results obtained in this study, we propose that a new variant of blue cheese might have been produced in Indonesia as the addition of microorganism that produces vitamin B12 and the fortification of folic acid and iron have successfully increased the amount of vitamin B12, folic acid, and iron in this new variant of blue cheese. These nutritional contents which are commonly deficient among the female populations contribute to the occurrence of anemia. Therefore, blue cheese produced in this study might have a potential to be developed into functional food for females.

As a suggestion for future research, the premix dose added in cheese should be optimized in order to increase the consumers' preference as well as to maintain the additional nutritional content in this blue cheese. The texture of the cheese could be improved by extending the ripening time (minimum 2 months) so as to reach a high score of preference in the sensory evaluation and to satisfy the consumers. We also suggest optimizing considerable amount of more homogenous table salt added to the curd in order to enhance the flavor of the blue cheese without causing serious health risks.

\section{ACKNOWLEDGEMENTS}

The authors thank Bank Mandiri for the financial support of the research, PT Indofood Sukses Makmur, Tbk and PT Natura Cheese for providing premix and rennet, and Mbrio Laboratory for providing excellent facilities and equipment for the chemical analysis.

\section{REFERENCES}

Boushey CJ, Beresford AA, Omen GS, Motulsky AG. 1996. A quantitative assessment of plasma homocysteine as a risk factor for vascular disease. JAm Med Assoc 274:1049-57.
Bronke Bailey LB. 1995. Folate intake recommendations from a nutritional science perspective. Cereal Foods World 40:63-6.

[BSN] National Standardization Organization. 1992. Food and drinks method of analysis. SNI 01-2891-1992.

[BSN] National Standardization Organization. 1998. Analysis of Fe, $\mathrm{Pb}$, $\mathrm{Cu}, \mathrm{Zn}, \mathrm{Sn}, \mathrm{Cd}, \mathrm{Ca}, \mathrm{K}$ and $\mathrm{Na}$ in liquid, solid and semi solid samples. SNI 19-2896-1998 point 4 and 5.

Caponio F, Pasqualone A, Gomes T. 2001. Apulian Cacioricotta goat's cheese: technical interventions for improving yield and organoleptic characteristics. Eur Food Res Technol 213:178-82.

Chen JH, Hotchkiss JH. 1991. Long shelf-life cottage cheese through dissolved carbon dioxide and high-barrier packaging. J Dairy Sci 74 (Suppl 1):125.

Daly LE, Kirke PN, Molloy A, Weir DG, Scott JM. 1995. Folate levels and neural tube defects. JAm Med Assoc 247:1698-702.

[FAO/WHO] Food and Agriculture Organization/World Health Organization. 2004. Vitamin and mineral requirements in human nutrition. $2^{\text {nd }}$ ed. Geneva: WHO \& FAO. p 246-300.

Forssén KM, Jägerstad MI, Wigertz K, Witthöft CM. 2000. Folates and dairy products: a critical update. JAm Coll Nutr 19:100S-10S.

Glynn SA, Albanes D. 1994. Folate and cancer: a review of the literature. Nutr Cancer 22:101-19.

Herbert V. 1988. Vitamin B-12: plant sources, requirements, and assay. Am J Clin Nutr 48:852-8.

Holstter G. 1994. Analytical methods for vitamin and food pharmapremix. Singapore: Roche. p 102-20.

Hotchkiss JH, Werner BG, Lee EYC. 2006. Addition of carbon dioxide to dairy products to improve quality: a comprehensive review. Comprehen Rev Food Sci Food Safety 5:158-68.

Hurrell RF. 1997. Preventing iron deficiency through iron fortification. Nutr Rev 55:210-22.

Keuth S, Bisping B. 1993. Formation of vitamins by pure cultures of tempe moulds and bacteria during the tempe solid substrate fermentation. J Appl Bacteriol 75:427-44.

Keuth S, Bisping B. 1994. Vitamin B12 production by Citrobacter freundii or Klebsiella pneumoniae during tempeh fermentation and proof of enterotoxin absence by PCR. Appl Environ Microbiol 60:1495-9.

Kosikowski F. 1982. Cheese and Fermented Milk Foods. New York: F.V. Kosikowski.

McLean E, Egli I, Cogswell M, Benoist B, Wojdyla D. 2007. Worldwide prevalence of anemia in preschool aged children, pregnant women and non-pregnant women of reproductive age. In: Kraemer $\mathrm{K}$, Zimmermann MB, editors. Nutritional anemia. Basel: Sight and Life Pr. p 112.

Morris MC, Evans DA, Bienias JL, Tangney CC, Hebert LE, Scherr PA, Schneider JA. 2005. Dietary folate and vitamin b12 intake and cognitive decline among community-dwelling older persons. Arch Neurol 62:641-5.

Shurtleff W, Aoyagi A. 1986. Tempeh production a craft and technical manual. Lafayette: The Soyfoods Center.

[WHO] World Health Organization. 2008. Worldwide prevalence of anaemia 19932005: WHO global database on anaemia. Geneva: WHO Pr.

Yasuda S, Ohkura N, Suzuki K, Yamasaki M, Nishiyama K, Kobayashi H, Hoshi Y, Kadooka Y, Igoshi K. 2010. Effects of highly ripened cheeses on HL-60 human leukemia cells: antiproliferative activity and induction of apoptotic DNA damage. J Dairy Sci 93:1393-400. 